\title{
Eurasian crane (Grus grus) as ecosystem engineer in grasslands - conservation values, ecosystem services and disservices related to a large iconic bird species
}

\author{
Orsolya Valkó ${ }^{1}$, Sándor Borza², Laura Godó², Zsolt Végvári² ${ }^{2}$, and Balázs Deák \\ ${ }^{1}$ Hungarian Academy of Sciences Centre for Ecological Research Institute of Ecology and \\ Botany and National Botanical Garden \\ ${ }^{2}$ Centre for Ecological Research
}

February 6, 2022

\begin{abstract}
Large bird species, such as cranes are involved in human-wildlife conflicts as they often forage in croplands. The Eurasian crane (Grus grus) is a large iconic bird species, protected across Europe, which, thanks to conservation programs and its ability to utilize croplands for foraging, shows a strongly increasing population trend. This exaggerates the already existing conflicts between crop farmers and cranes spilling over to natural habitats, where foraging by large flocks can lead to land degradation. To date, no studies have evaluated the effects of biopedturbation by cranes in grasslands, despite these habitats provide important feeding grounds for this large bird across its whole range. Here we evaluated the effect of biopedturbation by foraging Eurasian cranes on the vegetation of dry grasslands in Hungary. We used indicators of vegetation naturalness, forage quality and floral resource provision to evaluate the ecosystem state from multiple aspects. We sampled 100 quadrats in disturbed patches and 100 in intact grasslands in two seasons and two years (800 observations). We found that cranes created distinct habitat patches with different species composition compared to undisturbed areas. These early-successional patches that increased the plant diversity and floral resources but decreased the area of intact grasslands. Although crane-disturbed patches could provide forage for livestock early in the season, the forage quality of the vegetation became poor later in the year. Given the strong increase of the global crane population, monitoring the landscape-level extent of the disturbed areas, and developing a complex prevention and mitigation strategy would be important.
\end{abstract}

\section{Introduction}

Ecosystem engineer organisms create, alter, or maintain environmental conditions in a way that considerably affects several other organisms (Jones et al. 1994). The effect of engineer species varies across spatial scales (Coggan et al. 2018), from local microhabitat creation (e.g., several burrowing vertebrates create distinct microhabitat patches that provide shelter for other animals or establishment microsites for plants) to landscape-scale habitat alteration (e.g., beavers alter landscape-scape habitat structure and water flow that affect a wide range of species). Engineer animals mediate vegetation composition and dynamics through several mechanisms, including soil formation and affecting soil characteristics due to their metabolism (Clyde et al. 2021, Mallen-Cooper et al. 2018, Mosbech et al. 2018), forming establishment microsites through biopedturbation (Cavin \& Butler 2015, Davidson et al. 2012), or affecting seed dispersal and seedling establishment by scatter-hoarding (Godó et al. 2022, Pesendorfer et al. 2016).

Most studies on vertebrate engineers focus on mammals in general and rodents in particular (Mallen-Cooper et al. 2018). However, ecosystem engineering is also exemplified by charismatic birds, such as soil and sediment formation by seabirds or ducks on oceanic islands (Clyde et al. 2021, Mosbech et al. 2018), supporting forest recovery by scatter-hoarding corvids (Pesendorfer et al. 2016) or intentionally modifying fire regimes by 
raptors in Australia (Bonta et al. 2017). Ecosystem alteration by soil disturbance is rarely documented among birds and $96 \%$ of the studies on biopedturbation focus on mammals (Mallen-Cooper et al. 2015). Among birds, there are a few examples of burrow-nesting species, such as owls in deserts (Rengifo-Faiffer \& Arana 2019) or seabirds on oceanic islands (McKechnie 2006) that are known to affect local habitat conditions by biopedturbation during the construction and use of burrow systems. The burrow systems of birds and mammals are usually permanent landscape features as they are inhabited by successive generations of animals (Whitford \& Kay1999). These landscape features are often characterised by a unique vegetation. The structure and species composition of the vegetation developed on burrows are often distinct from the surrounding matrix, due to the continuous and concentrated trampling and nutrient input by the burrow dwellers (Valkó et al. 2021). Burrow networks can introduce a high level of environmental heterogeneity and biodiversity to the landscape (Cavin \& Butler 2015, Davidson et al. 2012, Valkó et al. 2021).

Biopedturbation during foraging might also be a relevant process in large-bodied birds inhabiting open landscapes, especially during migration when they forage in large flocks. Biopedturbation at foraging sites are probably less persistent landmarks as these areas are used only temporarily, but as large areas are affected worldwide this process might act as an important factor influencing habitat conditions in certain ecosystems. Despite the potential relevance of this process, we are not aware of any studies on the effect of biopedturbation by foraging birds on the species composition, structure or environmental conditions of natural habitats.

Ecosystem engineer animals, especially those creating biopedturbation are often involved in human-wildlife conflicts and face negative public attitudes. Their effects are often disputed as from the agricultural viewpoint they are often considered as pests but from the conservation viewpoint they are important keystone species. For example, the burrowing activity of the plateau pika (Ochotona curzoniae) provides a critical ecosystem service by increasing the infiltration rate of water, hence reducing overland flow at the Quinghai-Tibetean plateau (Wilson \& Smith 2015). Still, rangeland managers consider pikas as pests, because their burrowing activity can decrease the quality of the pasture, which resulted in mass poisoning campaigns that can have serious negative impacts on regional-scale hydrological functioning. As shown by the above example, maintenance of the integrity of essential ecosystem functions requires the gathering of evidence and informing the decision makers about the full spectrum of impacts, ecosystem services and disservices provided by engineer species. This might contribute to avoiding the damage to these important species and many others that depend on them. This is especially important given the conservation importance and threatened status of many ecosystem engineer species (Davidson et al. 2012). Their global decline goes beyond the loss of certain species and involves several cascading effects on the ecosystem structure and functionality.

Large bird species, such as majority of the 15 crane species of the world are involved in human-wildlife conflicts as they often forage in croplands, even though they mainly feed on crop residue (Austin et al. 2018). König et al. (2021) investigated the ecosystem services and disservices of four iconic animal species, one of them being the Eurasian crane (Grus grus). They found that the negative effects associated with crane presence were the moderate decrease of yield on croplands and increased labour and prevention costs that act at short term and local scales, affecting mostly private farmers. In contrast, several positive effects were found which were associated with cranes, as these iconic birds can support tourism, quality of life, cultural identity; and these middle- and long-term positive effects go beyond the local scale. Since not the same stakeholders experience the negative and positive effects, the effective conservation of cranes should include the compensation of those stakeholders (i.e., farmers) who are affected by the negative effects. The growing population trends of the world's two most abundant cranes - the sandhill (Antigone canadensis) and the Eurasian cranes - are associated with their ability to make use of the expansion of intensive agriculture by opportunistic foraging on croplands (Harris \& Mirande 2013, König et al. 2021). The growing abundance of these two crane species will probably further intensify the conflicts between cranes and farmers. There is a chance that these conflicts can spill over to natural habitats, where foraging by large flocks might lead to land degradation. The tendency for using technology that reduces crop residue might affect the habitat selection of cranes and might impose larger pressure on other habitat types including grasslands in the future (Nevard et al. 2018). In grasslands, farmer-wildlife conflicts and conflicts within the conservation sector can 
both occur if the intense disturbance by cranes decreases forage quality or naturalness of the vegetation.

Crane species foraging in grasslands occur in many parts of the world (Austin et al. 2018); for instance, the sandhill crane in North-America, the Eurasian crane and the demoiselle crane (Anthropoides virgo ) in many parts of Eurasia, the black-necked crane (Grus nigricollis ) in Tibet and the blue crane (Anthropoides paradiseus ) in South-Africa. Grazed grasslands provide suitable feeding grounds for cranes because livestock grazing recycles nutrients, keeps the landscape open, and supports large quantities of invertebrate food resources (Austin et al. 2018). Foraging crane flocks might have a considerable impact on grassland vegetation, although no studies evaluated the effects of biopedturbation by foraging cranes in grasslands.

The aim of our study was to evaluate the effect of biopedturbation by foraging Eurasian cranes on dry grassland vegetation. We used indicators for vegetation naturalness, forage quality and floral resource provision to evaluate the ecosystem state from multiple aspects. We specifically asked the following questions: (i) Do the species composition and structure of the vegetation differ in grasslands used as forage sites by cranes from intact grasslands? (ii) Which plant functional groups are supported and suppressed by biopedturbation of the cranes? (iii) How does biopedturbation by cranes affect the diversity and naturalness of the vegetation? (iv) Does soil disturbance by cranes affect forage quality and floral resources? Our study can contribute to the understanding of the ecosystem services and disservices provided by a large iconic bird species in grasslands. The results can be relevant not only for the Eurasian crane but also for the other crane species.

\section{Materials and methods}

Study system

The study sites are located in the Hortobágy National Park, East Hungary (Figure 1). Hortobágy is one of the largest continuous open landscape in Europe where alkaline grasslands cover approximately 80000 hectares. The climate is temperate continental, with a mean annual temperature of $9.5^{\circ} \mathrm{C}$ and mean annual precipitation of $550 \mathrm{~mm}$ (Fick \& Hijmans 2017). The soil reference group of the study area is classified as Vertic Solonetz, characterised by high salt content (IUSS Working Group 2015). Hortobágy is a lowland plain area, the elevation ranges between 87 and $110 \mathrm{~m}$ above sea level. The landscape is characterised by a high diversity of dry grassland, wet meadow and marsh habitats as well as a small amount of croplands. Alkaline grasslands, meadows and marshes are included in the Annex I of the Habitats Directive (92/43/EEC) as "Pannonic salt steppes and salt marshes (1530)", a priority habitat type of the European Union. The most widespread dry grassland type is Achilleo setaceae - Festucetum pseudovinae, which are short, dry grasslands that occur on moderately alkaline soil and are managed by extensive grazing. The dominant grass species covering $50-80 \%$ of the vegetation is Festuca pseudovina, characteristic forb species include Achillea collina , A. setacea, Plantago lanceolata, Podospermum canum and Trifolium spp. (Deák et al. 2014).

The Eurasian crane (Grus grus ) is a large-bodied bird species with a Palaearctic distribution. Its global population is currently strongly increasing and estimated as approximately 500000 individuals (Wetlands International 2015). It is a protected bird species in Hungary and across the European Union, being a bird of community interest and listed in the Annex I of the Birds Directive (2009/147/EC). Hortobágy is the largest stopover area during Baltic-Hungarian Flyway, connecting the eastern part of Scandinavia, western Russia, the Baltic states and Tunisia, crossing Poland, Hungary and the Balkan Peninsula. During autumn migration, the highest crane numbers can be observed between mid-September and late November. Since 2000, the total number of cranes found simultaneously roosting at the Hortobágy National Park has exceeded 150,000 individuals several times and averaged over 130,000 birds (database of the Hortobágy National Park Directorate). The peak number of cranes recorded at the Hortobágy National Park were 158740 in the autumn 2019 and 95400 in 2020 (www.hnp.hu).

While staying in the Hortobágy, the cranes spend most part of daytime in foraging on croplands, especially in maize stubbles, whereas they occasionally also utilize grasslands as feeding habitats (Végvári 2002). They spend the nights on fishponds where they are more protected from predators. In grasslands, cranes display a special feeding habit that is called as 'crane-ploughing'. This means that the birds search for invertebrates in the grasslands (Anteau et al., 2011) and during this activity they heavily disturb the soil surface using 
their bills. The disturbed soil surface resembles a ploughed area (Figure 1). The area of ploughs typically ranges between 10-100 $\mathrm{m}^{2}$, but occasionally, larger ploughings also occur.

Study sites and sampling

We designated ten study sites in October 2019 when the soil disturbance made by the cranes are the most apparent on the sites. We used the following criteria for site selection: 1, the sites were situated at least $1 \mathrm{~km}$ from each other, 2 , the sites were characterised by dry alkaline grassland vegetation (Achilleo setaceae Festucetum pseudovinae ); 3, all the sites were managed by extensive grazing, 4) within each site vegetation patches disturbed by cranes as well as undisturbed areas occurred within a distance of $0.5 \mathrm{~km}$ in alkaline dry grasslands and 5) the disturbed and intact areas were at least $50 \mathrm{~m}^{2}$ large.

Within each site we designated two $30 \mathrm{~m}^{2}$-sized permanent plots; one in disturbed area and one in intact grassland. In October 2020 we re-visited all the sites to record whether the areas disturbed in 2019 were disturbed again in 2020 and whether the areas undisturbed in 2019 remained intact also in 2020. In each plot, we designated ten $1 \mathrm{~m} \times 1 \mathrm{~m}$ sized quadrats, which were precisely marked with metal sticks placed underground so we could precisely re-visit the quadrats with the help of a metal detector. In total there were 100 ploughed and 100 undisturbed quadrats.

We recorded the species list and percentage cover of vascular plant species in each quadrat at four sampling dates: early April 2020, mid-June 2020, early April 2021 and mid-June 2021. This resulted in 800 observations in total. Nomenclature of vascular plants followed the work of Király (2009). We also recorded the total cover of vascular plants and that of cryptogams (i.e., the summed cover of mosses, lichens and Nostoc cyanobacteria). 

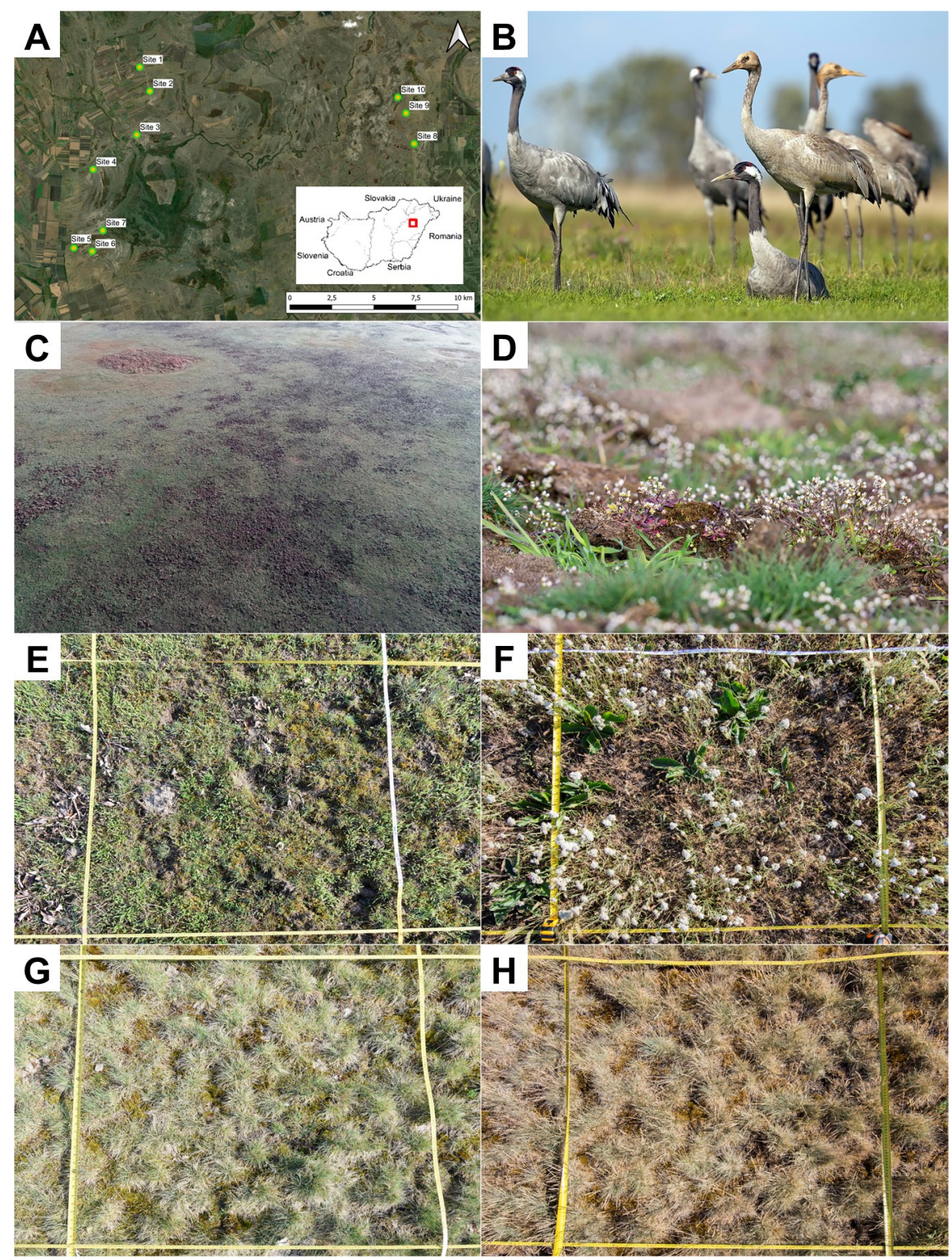

Figure 1. A - location of the study sites, B - Eurasian cranes, C - grassland disturbed by cranes from the bird-eye's view, D - early successional vegetation with the dominance of Erophila verna on a disturbed patch; E - vegetation of a crane-disturbed quadrat in April 2021; F - vegetation of the same quadrat in June 2021; G - vegetation of an intact grassland quadrat in April 2021; H - vegetation of the same quadrat in June 2021. Photos were taken by Attila Szilágyi (B), Sándor Borza (C) and Laura Godó (D-H).

Data analysis

We assigned the recorded vascular plant species to four morphological groups: short-lived forbs, short-lived graminoids, perennial forbs and perennial graminoids. The full list of the recorded species and their assignment to morphological groups are provided in Appendix 1.

We used two proxies for conservation values: Shannon diversity and naturalness score. We calculated the Shannon diversity of the vascular plant species in each plot. For expressing the naturalness of the vegetation, we classified the recorded plant species into Social Behaviour Types (SBT) according to the classification 
system of Borhidi (1995). The classification system assigns a naturalness value to each SBT category, ranging from -3 ( $\mathrm{AC}$ - adventive competitors) to +10 ( $\mathrm{Su}$ - unique specialist species). We calculated cover-weighted naturalness scores for all plots.

We used two proxies of forage quality: a Hungarian classification system (Balázs 1949) that takes multiple palatability criteria into account and specific leaf area (SLA), which is a proxy for hydrated and more attractive leaves. We classified the species according to their forage quality based on the classification system of Balázs (1949). Forage quality scores range from -3 (toxic plants) to +8 (highly valuable forage plants). The average of the reported SLA values was derived from a regional database (E.-Vojtkó et al. 2020) and for the species not represented in the regional database, the LEDA database (Kleyer et al. 2008) was used. We calculated cover-weighted forage quality and SLA scores for all plots.

We characterised the availability of floral resources with two proxies: flowering period and the cover of insectpollinated species. Flowering period was calculated as the number of months when a species is flowering using the work of Király (2009). We calculated the community-weighted means (CWM) of flowering period for all plots.

We used repeated measures general linear models (RM-GLMs) for testing the effect of disturbance (two levels: disturbed plots, intact grasslands; fixed factor), year (two levels: 2020, 2021; repeated measures factor) and season (two levels: spring, summer; repeated measures factor). All possible interactions between the factors were included in the models. Dependent variables were: total vegetation cover, cryptogam cover, perennial forb cover, perennial graminoid cover, short-lived forb cover, short-lived graminoid cover, Shannon diversity, naturalness score, forage quality score, specific leaf area, CWM of flowering period and the cover of insectpollinated plants. All univariate statistics were calculated using the GLM repeated measures command in IBM SPSS Statistics v. 20.0 (Armonk, NY: IBM Corp).

To assess the species composition of the vegetation in the disturbed plots and intact grasslands across the two study years and two seasons, non-metric multidimensional scaling (NMDS) based on percentage cover of the species was calculated using CANOCO 5.0 program (Ter Braak \& Šmilauer 2012). For the multivariate analysis, quadrats from the same plot, season and year were averaged.

To investigate if plant abundances differed among i) disturbance types (disturbed plots vs. intact grasslands), ii) years (2020 vs. 2021) and iii) seasons (spring vs. summer), we applied permutational analysis of variance (PERMANOVA). To do so, first we calculated a continuous distance matrix using the raw abundance records of each of the 68 plant species, considering Bray-Curtis distance coefficients. In the following step, we fitted six PERMANOVA tests treating types, years, and seasons as well as their interactions as grouping factors in comparison with abundance distances, employing the PERMANOVA function available in the "PERMANOVA" package (Vicente-Gonzalez \& Vicente-Villardon 2021) of the R statistical programming environment (R Core Team 2021).

\section{Results}

Species composition

In total we recorded 68 vascular plant species, out of which 62 species occurred in the disturbed plots and 57 in the intact grasslands. Species composition of the disturbed plots and intact grasslands were separated along the horizontal axis of the NMDS ordination (Figure 2). Characteristic species of the disturbed areas included early-successional short-lived forb (Erophila verna, Myosotis stricta, Polygonum aviculare) and graminoid (Bromus hordeaceus, Poa bulbosa) species, and several disturbance-tolerant perennial forbs, such as Achillea collina,A. setacea and Plantago lanceolata. Intact grasslands were characterised by perennial graminoids, such as Festuca pseudovina, Elymus repens and Carex stenophylla. We observed a separation between spring and summer vegetation in the crane-disturbed plots, while the species composition of intact grasslands was similar across seasons. There was no clear separation in the vegetation between the two years.

The PERMANOVA analysis confirmed the patterns of the ordination. The species composition of the disturbed plots and the intact grasslands was significantly different $(\mathrm{F}=40.11, p=0.048)$. The vegetation 
was different between the two seasons $(\mathrm{F}=2.62, \mathrm{p}=0.001)$ but there was no separation among years $(\mathrm{F}=1.69, p=0.131)$. The interaction of disturbance $\times$ year $(\mathrm{F}=14.52, p=0.001)$ and disturbance $\times$ season $(\mathrm{F}=15.52, p=0.001)$ resulted in significantly different species compositions, while year $\times$ season interaction $(\mathrm{F}=1.61, p=0.101)$ had no effect on vegetation composition.

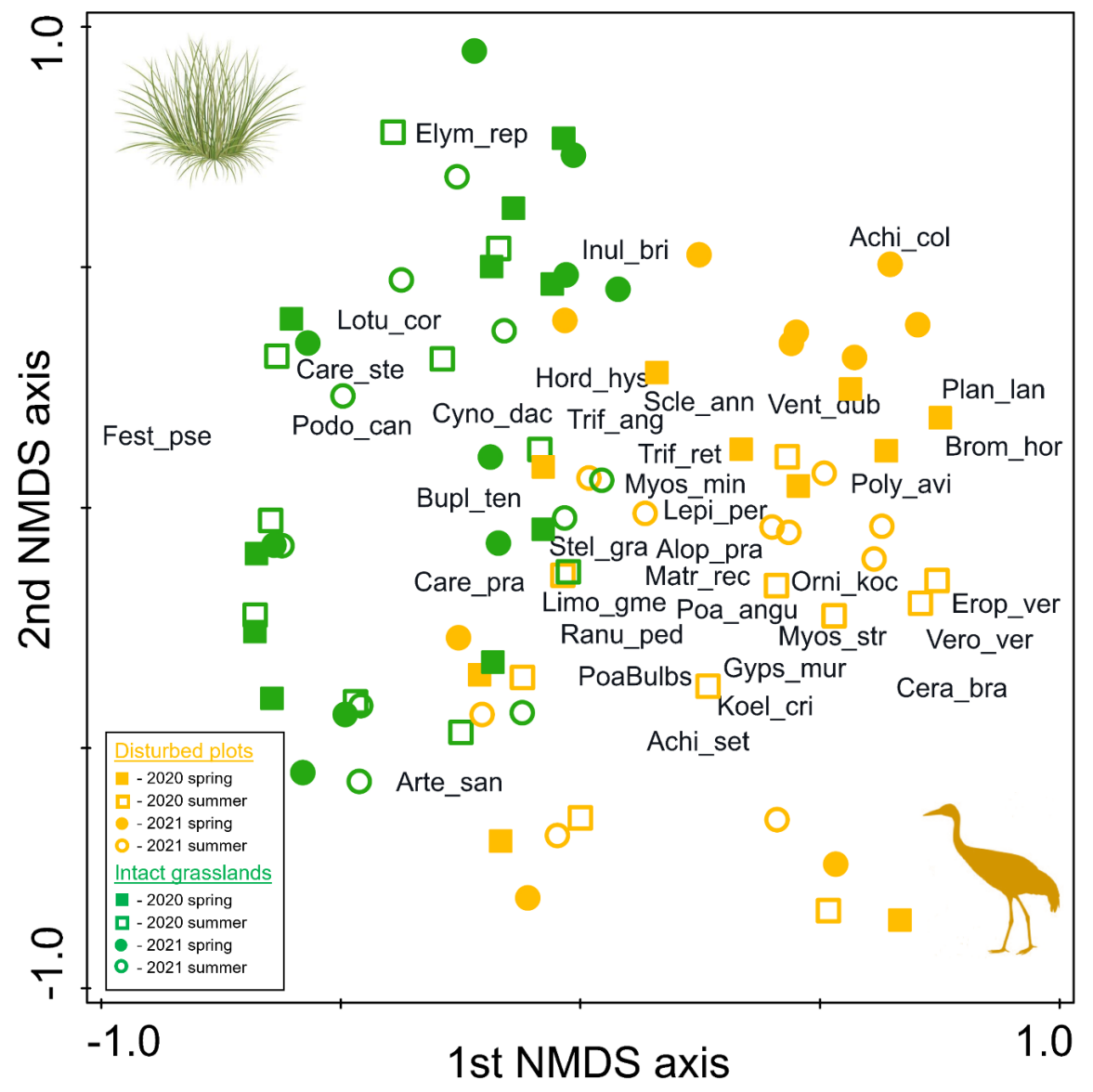

Figure 2 . Non-metric multidimensional scaling (NMDS) of disturbed plots and intact grasslands in the two study years and two seasons. Notations: yellow symbols - disturbed plots; green symbols - intact grasslands; squares - year 2020, circles - year 2021; empty symbols - spring; full symbols - summer. Species names are abbreviated by using the first four letters of the genus and first three letters of the species names (for the full list, please see Appendix 1). Eigenvalues for the first and second axis were 0.573 and 0.235 . Cumulative explained variance of the first and second axis were $57.30 \%$ and $80.81 \%$.

Plant functional groups, conservation values and ecosystem services

All the plots disturbed in 2019 were disturbed again in 2020, while all plots intact in 2019 remained intact also in 2020. The effect of disturbance was significant on all the studied parameters (Table 1). Total vegetation cover, cryptogam cover and the cover of perennial graminoids were smaller in the disturbed plots than in the intact grasslands, while perennial forbs, short-lived forbs and short-lived graminoids were more abundant in the disturbed plots (Figure 3A-F). The disturbed plots were characterised by larger Shannon diversity (Figure 4A) and smaller naturalness score (Figure 4B) than the intact grasslands. Forage quality (Figure 4C) decreased and specific leaf area (Figure 4D) increased as a result of the disturbance. Plant species tended to have longer flowering period in the disturbed plots (Figure 4E). The cover of insect-pollinated plants was larger in the disturbed plots compared to the intact grasslands (Figure $4 \mathrm{~F}$ ). 
We identified significant interaction terms (Table 1) which shows that the effect of disturbance on the vegetation characteristics were mediated by year (in case of 7 variables), season (in case of 7 variables), or the interaction of year and season (in case of 6 variables). Vegetation changes were consistent in the intact grasslands across the study years and seasons.
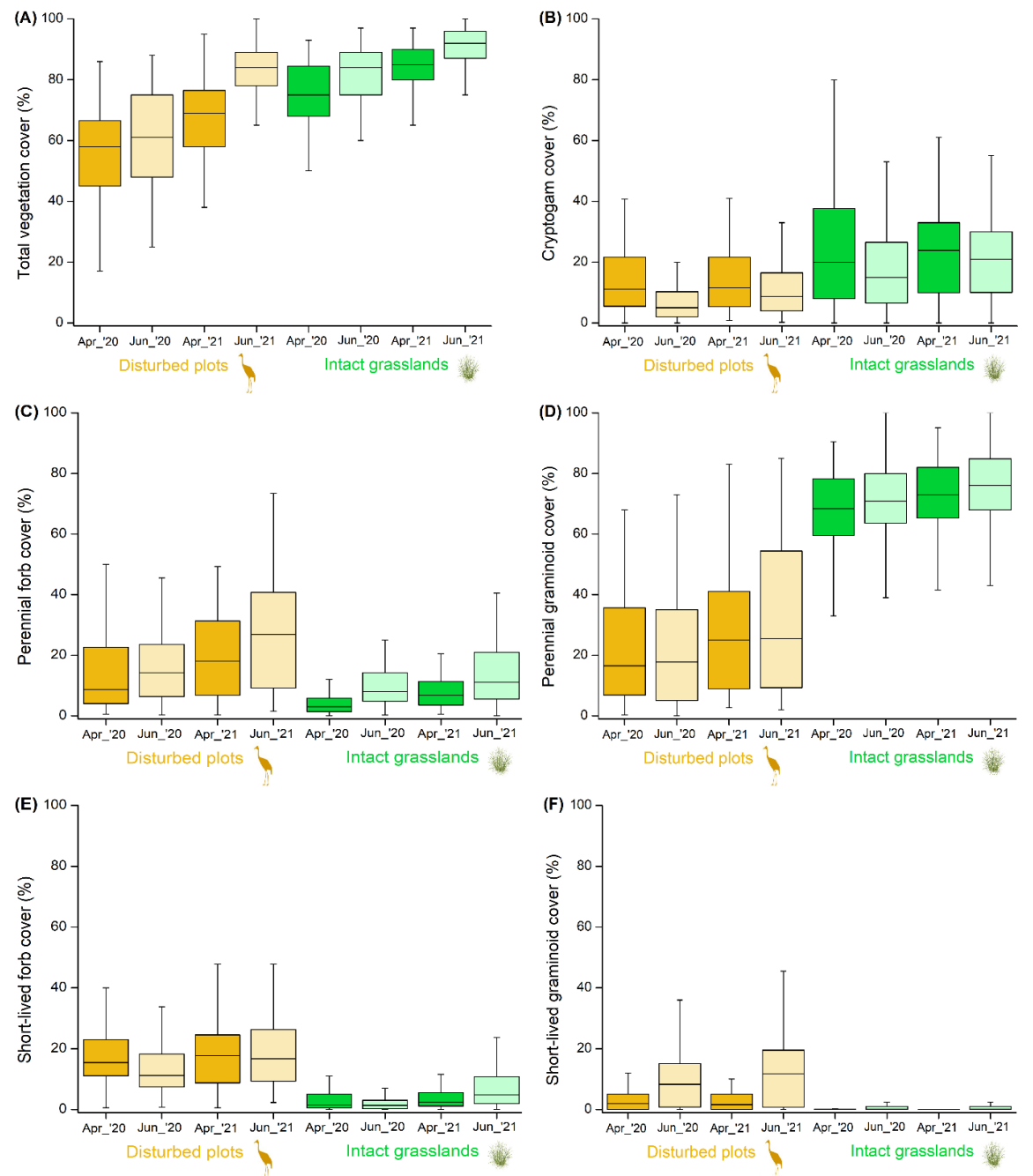

Figure 3. Vegetation characteristics related to vegetation structure and plant functional groups in the disturbed plots (orange boxes) and intact grasslands (green boxes) in the two study years $(2020,2021)$ and two seasons (spring - Apr, summer - Jun). 

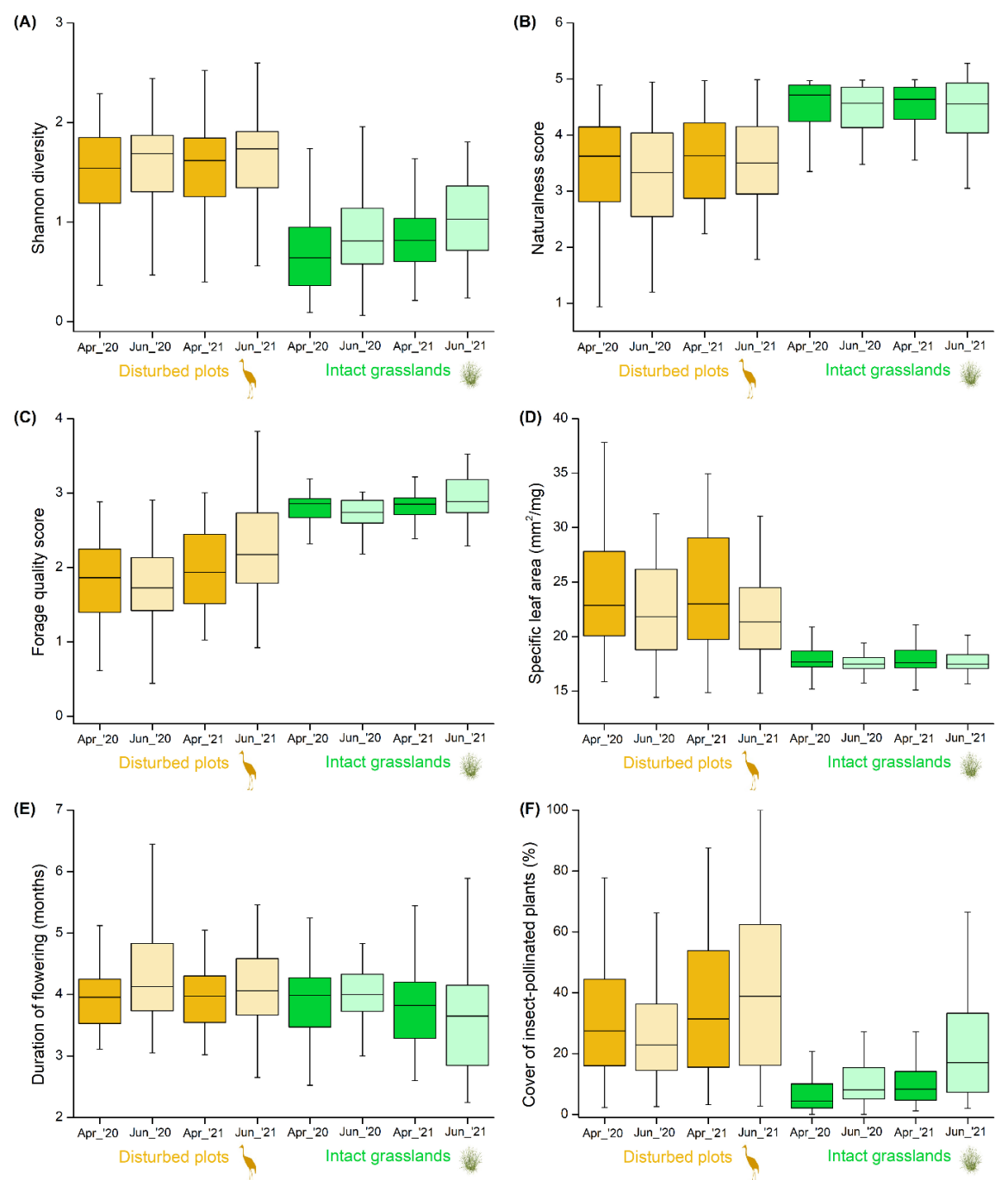

Figure 4. Vegetation characteristics related to ecosystem state in the disturbed plots (orange boxes) and intact grasslands (green boxes) in the two study years $(2020,2021)$ and two seasons (spring - Apr, summer - Jun).

Table 1. The results of the repeated-measures general linear models testing the effect of Type (disturbed plots vs. intact grasslands; fixed factor), Year (2020 vs. 2021; repeated measures factor) and Season (spring vs. summer; repeated measures factor) and their interactions (Type $\times$ Year, Type $\times$ Season, Year $\times$ Season, Type $\times$ Year $\times$ Season) on the dependent variables related to vegetation structure, plant functional groups and ecosystem state. Significant effects (p [?] 0.05) are denoted by boldface and grey highlight.

\begin{tabular}{lllllllll}
\hline Factors & Type & Type & Year & Year & Season & Season & Type $\times$ Year & Type $\times$ \\
\hline Dependent variables & $\mathbf{F}$ & $\mathbf{p}$ & $\mathbf{F}$ & $\mathbf{p}$ & $\mathbf{F}$ & $\mathbf{p}$ & $\mathbf{F}$ & $\mathbf{p}$ \\
Total vegetation cover & $\mathbf{6 2 . 9 9 3}$ & $\mathbf{0 . 0 0 0}$ & $\mathbf{5 4 . 9 9 2}$ & $\mathbf{0 . 0 0 0}$ & $\mathbf{1 2 . 9 3 1}$ & $\mathbf{0 . 0 0 0}$ & 0.858 & 0.355 \\
Cryptogam cover & $\mathbf{3 3 . 9 3 6}$ & $\mathbf{0 . 0 0 0}$ & 1.672 & 0.198 & $\mathbf{1 0 7 . 0 9 2}$ & $\mathbf{0 . 0 0 0}$ & 0.118 & 0.731 \\
Perennial forb cover & $\mathbf{4 4 . 3 4 9}$ & $\mathbf{0 . 0 0 0}$ & $\mathbf{7 8 . 6 6 5}$ & $\mathbf{0 . 0 0 0}$ & $\mathbf{1 8 2 . 8 7 8}$ & $\mathbf{0 . 0 0 0}$ & 3.788 & 0.053 \\
Perennial graminoid cover & $\mathbf{4 0 0 . 7 9 2}$ & $\mathbf{0 . 0 0 0}$ & $\mathbf{6 2 . 4 1 1}$ & $\mathbf{0 . 0 0 0}$ & $\mathbf{3 2 . 8 1 6}$ & $\mathbf{0 . 0 0 0}$ & 1.214 & 0.272 \\
Short-lived forb cover & $\mathbf{1 9 2 . 3 2 0}$ & $\mathbf{0 . 0 0 0}$ & $\mathbf{3 3 . 5 9 6}$ & $\mathbf{0 . 0 0 0}$ & 0.094 & 0.759 & 0.197 & 0.658
\end{tabular}




\begin{tabular}{lllllllll}
\hline Factors & Type & Type & Year & Year & Season & Season & Type $\times$ Year & Type $\times$ \\
\hline Short-lived graminoid cover & $\mathbf{6 6 . 3 4 5}$ & $\mathbf{0 . 0 0 0}$ & $\mathbf{4 . 5 0 1}$ & $\mathbf{0 . 0 3 5}$ & $\mathbf{9 3 . 3 0 0}$ & $\mathbf{0 . 0 0 0}$ & $\mathbf{5 . 6 3 6}$ & $\mathbf{0 . 0 1 9}$ \\
Shannon diversity & $\mathbf{1 6 6 . 6 6 5}$ & $\mathbf{0 . 0 0 0}$ & $\mathbf{5 0 . 1 0 7}$ & $\mathbf{0 . 0 0 0}$ & $\mathbf{1 1 2 . 3 7 0}$ & $\mathbf{0 . 0 0 0}$ & $\mathbf{1 0 . 4 0 1}$ & $\mathbf{0 . 0 0 1}$ \\
Naturalness score & $\mathbf{9 7 . 2 9 2}$ & $\mathbf{0 . 0 0 0}$ & $\mathbf{5 . 8 1 4}$ & $\mathbf{0 . 0 1 7}$ & $\mathbf{1 3 . 6 4 2}$ & $\mathbf{0 . 0 0 0}$ & $\mathbf{4 . 8 5 9}$ & $\mathbf{0 . 0 2 9}$ \\
Forage quality score & $\mathbf{2 4 5 . 3 5 0}$ & $\mathbf{0 . 0 0 0}$ & $\mathbf{5 3 . 7 5 2}$ & $\mathbf{0 . 0 0 0}$ & $\mathbf{4 . 9 5 7}$ & $\mathbf{0 . 0 2 7}$ & $\mathbf{1 4 . 3 9 1}$ & $\mathbf{0 . 0 0 0}$ \\
Specific leaf area & $\mathbf{1 2 2 . 5 5 3}$ & $\mathbf{0 . 0 0 0}$ & $\mathbf{7 . 6 5 3}$ & $\mathbf{0 . 0 0 6}$ & $\mathbf{8 5 . 7 5 7}$ & $\mathbf{0 . 0 0 0}$ & $\mathbf{4 . 9 1 3}$ & $\mathbf{0 . 0 2 8}$ \\
Flowering period & $\mathbf{7 . 6 3 1}$ & $\mathbf{0 . 0 0 6}$ & $\mathbf{2 6 . 0 0 2}$ & $\mathbf{0 . 0 0 0}$ & $\mathbf{1 2 . 6 3 1}$ & $\mathbf{0 . 0 0 1}$ & $\mathbf{7 . 3 7 2}$ & $\mathbf{0 . 0 0 7}$ \\
Cover of insect-pollinated species & $\mathbf{1 0 8 . 5 4 1}$ & $\mathbf{0 . 0 0 0}$ & $\mathbf{9 6 . 9 5 5}$ & $\mathbf{0 . 0 0 0}$ & $\mathbf{2 3 . 4 9 0}$ & $\mathbf{0 . 0 0 0}$ & $\mathbf{5 . 4 8 9}$ & $\mathbf{0 . 0 2 0}$ \\
\hline
\end{tabular}

\section{Discussion}

Vegetation composition of crane-disturbed vs. intact patches

We found that biopedturbation by foraging cranes created habitat patches with different vegetation structure and species composition compared to undisturbed stands of dry alkaline grasslands. The disturbed patches were characterised by sparse vegetation with small cover of vascular plants and cryptogams. The cover of perennial graminoids decreased, while that of perennial forbs and short-lived graminoids and forbs increased as a result of crane ploughing. The availability of open microsites and the low cover of competitor perennial graminoid species probably supported the germination of several plant species which resulted in larger plant diversity in disturbed areas compared to intact grassland (Deák et al. 2011). Similar patterns were found in Peruvian deserts where avian biopedturbations by burrow-nesting birds created more favourable areas for seedling establishment compared to undisturbed patches (Rengifo-Faiffer \& Arana 2019).

In their meta-analysis Romero et al. (2014) showed that the overall effect of ecosystem engineers on diversity is positive and corresponds to a $25 \%$ increase in species richness, indicating that ecosystem engineering is a facilitative process globally. We detected a significant, approximately two-fold increase in plant diversity in the crane-disturbed plots compared to intact grasslands. This is particularly interesting, as such strong effect of engineer species has not been found for foraging bird species before and engineer effect was reported to be weaker at latitudes higher than $23^{\mathrm{O}}$ (Romero et al. 2014).

The species composition of disturbed and intact areas was clearly separated as shown by the multivariate analysis which implies that cranes create distinct habitat patches within the grasslands. Disturbed patches were characterised by early successional short-lived graminoids and forbs that are natural elements of the open, trampled and grazed patches of alkaline grasslands (Deák et al. 2015). Invasive or strong competitor weed species were absent on the disturbed plots, which might be due to the high salt content of the soil (see also Valkó et al. 2017). The disturbed plots were characterised by high inter-annual vegetation fluctuation, while this seasonality was less apparent in the intact grasslands.

\section{Conservation values, ecosystem services and disservices}

We observed increased diversity but decreased naturalness score in the crane-disturbed patches. This was due to the high cover of early-successional natural pioneer and disturbance-tolerant species and lower cover of generalists and competitors, especially Festuca pseudovina, the dominant grass species of alkaline grasslands. Patches of early-successional vegetation formed by grazing animals are integral parts of the studied ecosystem, so in the current extent, these early-successional patches do not pose a considerable conservation problem (Deák et al. 2015, Valkó et al. 2017).

We evaluated the effects of crane biopedturbation on the forage quality of grasslands using two proxies. Forage quality expressed by the Balázs-score was lower in the disturbed patches compared to intact grasslands, as crane ploughings are characterised by pioneer species that sprout and dry out early in the season, so they do not provide suitable forage in the summer and autumn (Balázs 1949). This implies that in large extent, crane biopedturbation can be problematic for grazing management. However, the negative consequences of decreased overall forage quality in the disturbed patches can be counterbalanced by the increased availability 
of forage plants in early spring. SLA is another proxy of forage quality, as livestock tends to select species with fresh, hydrated leaves characterised by large SLA (Balogh et al. 2021). We found that the disturbed patches were characterised by plants with larger SLA. This can be important for grazing management especially in the springtime, where the early-sprouting pioneer vegetation formed on the disturbed patches can provide important complementary forage for the livestock compared to the intact grasslands. The fresh sprouts of short-lived graminoids (such as Bromus hordeaceus, Hordeum hystrix and Poa bulbosa) growing on crane-disturbed areas can provide good forage for livestock in early spring (Molnár 2017).

We found that crane-disturbed areas provided floral resources for a longer time and in larger quantity compared to intact grassland. This can support the maintenance of insect diversity, especially pollinator assemblages and palynivores (Bátori et al. 2020). This service has an especially high conservation importance in grass-dominated habitats such as the studied ecosystem with relatively few nectar-producing plants. Similar phenomenon was reported on the burrows of Siberian marmots (Marmota sibirica), where the larger number of flowers and their higher visibility attracted more pollinators compared to undisturbed grasslands (Yoshihara et al. 2010).

\section{Conclusions}

Our results suggest that the effects of biopedturbation by cranes from the conservation and rangeland management viewpoint are complex. Cranes create early-successional open habitat patches that increase the landscape-scale biodiversity and floral resources but decrease the area of intact alkaline grasslands. Cranedisturbed patches can provide forage for livestock early in the season, but later on the forage quality of the vegetation becomes poor. Soil disturbance similar to crane ploughings have been an important component of many open landscapes. Indeed, creating such focal soil perturbations artificially was found to be effective for increasing environmental heterogeneity and provide establishment microsites for subordinate plant species (Limb et al. 2010).

Due to the site fidelity of cranes, biopedturbations seem to be permanent landscape elements, that are maintained in an early successional stage across years. It is an interesting question for future studies why do cranes prefer their already used foraging sites and whether their foraging activity and the associated disturbance increase the abundance of some of their preferred food items, such as certain soil-dwelling arthropods. Given the increasing global population of Eurasian cranes (Wetland International 2015) and the mild winters as a consequence of climate change, it is expected that cranes will be more abundant and stay for longer in stopover areas, and the number of overwintering birds is also expected to increase (König \& Mirande 2013). This predicted increase in crane pressure will probably affect not only the grassland patches currently used for foraging but also currently intact grasslands as well. Additionally, the current warming trends of the winters across Europe have already resulted in the northward shift of the wintering ranges of the Eurasian Crane. For example, significant part of the Northwest-European breeding population of the study species has shifted its wintering grounds by over 1000 kilometres within 15 years (Prange 1999). As observational evidence is mounting that the same behavioural change is happening in the Baltic-Hungarian Flyway, the effects of the ploughing of cranes are expected to be stronger in winter than in the autumn months, owing to the increasingly wet soil conditions. This might amplify the transformation of local habitat patches. Therefore, a surveillance system monitoring the landscape-level extent of the disturbed areas, e.g., by satellite imagery would be important to keep track on the vegetation changes.

In case the crane pressure considerably increases in the future, prevention or mitigation actions will be necessary to avoid land degradation. Increased crane pressure in grasslands will cause a conflict within the nature conservation sector: a strictly protected species in strictly protected areas can cause the degradation of the strictly protected habitat. Such conflict can only be managed with a complex prevention and mitigation strategy.

One option would be to use visual clues that can make the focal grassland areas unattractive for cranes. Scarecrows or other devices have been used for such purposes in croplands with mixed success: this option works mostly against small groups of birds and items should be moved or animated because the cranes can 
quickly habituate to constant objects (Austin et al. 2018). Using scary visual clues can be an option on some particular localities, but cannot provide a full solution for decreasing crane pressure in the whole 80000 hectares of grassland area in the study region. Other options developed for scaring cranes from croplands (e.g., fencing or using audial clues) cannot work in grasslands inside a nature reserve.

A potentially effective prevention strategy would be to maintain the currently used croplands in the stopover areas to provide primary feeding grounds for cranes and to avoid a considerably larger crane pressure on grasslands (Végvári 2002). In these areas, cultivation of corn would be the best option, as its crop residue is a preferred food item of cranes. Experimental studies are required to analyse the habitat preferences of the Eurasian crane during wintering that helps outlining management plans which distract cranes from sensitive grasslands, which needs to be incorporated into national and international agricultural subsidising systems.

Among management strategies, grassland restoration on disturbed surfaces might be an option. As alkaline grasslands have a good spontaneous recovery potential, passive restoration should be supported in smaller disturbed patches (Valkó et al. 2017). Active restoration by seed sowing should be only used on large disturbed patches where the likeliness of spontaneous recovery is lower, but in this case the trampling and other disturbance associated with restoration measures can be harmful for the surrounding intact grassland areas.

It is important to note that in less harsh environments, intense biopedturbation by cranes might be of greater concern due to the possible encroachment of weed and invasive plant species that were limited by the harsh environmental conditions in our studied system. We can also expect that in lower latitudes the engineering effect of cranes can be even higher (Romero et al. 2014). These call for future studies in other ecoregions and habitat types.

\section{Acknowledgements}

We are grateful to Attila Szilágyi for providing a photo for Figure 1. The authors were supported by the Hungarian National Research, Development and Innovation Office (grant numbers: KDP 967901 - SB, FK 124404 - OV, FK 135329 - BD, MEC_R 141154 - SB).

\section{Conflict of Interest Statement}

The authors declare no conflict of interest.

\section{References}

Anteau MJ, Sherfy MH, Bishop AA, 2011. Location and agricultural practices influence spring use of harvested cornfields by cranes and geese in Nebraska. Journal of Wildlife Management 75: 1004-1011.

Austin, J. E., Morrison, K., \& Harris, J. T. (2018). Cranes and agriculture: a global guide for sharing the landscape. International Crane Foundation, Baraboo, Wisconsin, USA.

Balázs, F. (1949): A gyepek termésbecslése növénycönológia alapján (Yield estimation of grasslands based on plant coenology) [in Hungarian]. -Agrártudományok 1: 25-35.

Balogh, N., Tóthmérész, B., Valkó, O., Deák, B., Tóth, K., Molnár, Zs., Vadász, Cs., Tóth, E., Kiss, R., Sonkoly, J., Antal, K., Tüdôsné Budai, J., Miglécz, T., Kelemen, A. (2021): Consumption rate and dietary choice of cattle in species-rich mesic grasslands. Tuexenia 41: 395-410.

Bátori, Z., Kiss, P.J., Tölgyesi, C., Deák, B., Valkó, O., Török, P., Erdôs, L., Tóthmérész, B., Kelemen, A. (2020): River embankments mitigate the loss of grassland biodiversity in agricultural landscapes. River Research and Applications 36 (7): 1160-1170.

Bonta, M., Gosford, R., Eussen, D., Ferguson, N., Loveless, E., \& Witwer, M. (2017). Intentional firespreading by "Firehawk" raptors in Northern Australia. Journal of Ethnobiology, 37(4), 700-718.

Borhidi, A., 1995. Social behaviour types, the naturalness and relative ecological indicator values of the higher plants in the Hungarian Flora. Acta Bot. Hung. 39, 97-181. 
Cavin, R. M., \& Butler, D. R. (2015). Patterns and trends in the fields of bioturbation, faunalturbation, and zoogeomorphology. Physical Geography, 36(3), 178-187.

Clyde, N., Hargan, K. E., Forbes, M. R., Iverson, S. A., Blais, J. M., Smol, J. P., .. \& Gilchrist, H. G. (2021). Seaduck engineers in the Arctic Archipelago: nesting eiders deliver marine nutrients and transform the chemistry of island soils, plants, and ponds. Oecologia, 195(4), 1041-1052.

Coggan, N. V., Hayward, M. W., \& Gibb, H. (2018). A global database and "state of the field" review of research into ecosystem engineering by land animals. Journal of Animal Ecology, 87(4), 974-994.

Davidson, A. D., Detling, J. K., \& Brown, J. H. (2012). Ecological roles and conservation challenges of social, burrowing, herbivorous mammals in the world's grasslands. Frontiers in Ecology and the Environment, 10, $477-486$.

Deák, B., Valkó, O., Kelemen, A., Török, P. Miglécz, T., Ölvedi, T., Lengyel, Sz., Tóthmérész, B. (2011): Litter and graminoid biomass accumulation suppresses weedy forbs in grassland restoration. Plant Biosystems 145: 730-737.

Deák, B., Valkó, O., Alexander, C., Mücke, W., Kania, A., Tamás, J., Heilmeier, H., 2014. Fine-scale vertical position as an indicator of vegetation in alkali grasslands - case study based on remotely sensed data. Flora 209, 693-697.

Deák, B., Valkó, O., Török, P., Kelemen, A., Miglécz, T., Szabó, S., Szabó, G., Tóthmérész, B., 2015. Microtopographic heterogeneity increases plant diversity in old stages of restored grasslands. Basic Appl. Ecol. 16, 291-299.

E.-Vojtkó, A., Balogh, N., Deák, B., Kelemen, A., Kis, Sz., Kiss, R., Lovas-Kiss, Á., Löki, V., Lukács, K., Molnár V., A., Nagy, T., Sonkoly, J., Süveges, K., Takács, A., Tóth, E., Tóth, K., Tóthmérész, B., Török, P., Valkó, O., Vojtkó, A., Lukács, B.A. (2020): Leaf trait records of vascular plant species in the Pannonian flora with special focus on endemics and rarities. Folia Geobotanica 55: 73-79.

Fick, S.E., Hijmans, R.J., 2017. WorldClim 2: new 1-km spatial resolution climate surfaces for global land areas. Int. J. Climatol. 37(12), 4302-4315. https://doi.org/10.1002/joc.5086.

Godo, L., Valko, O., Borza, S., Deak, B. (2022): A global review on the role of small rodents and lagomorphs (clade Glires) in seed dispersal and plant establishment. Global Ecology and Conservation 33: e01982.

Harris, J., \& Mirande, C. (2013). A global overview of cranes: status, threats and conservation priorities. Chinese Birds, 4(3), 189-209.

IUSS Working Group, 2015. WRB. World Reference Base for Soil Resources 2014, update 2015. International soil classification system for naming soils and creating legends for soil maps. World Soil Resources Reports No. 106. FAO, Rome.

Jones, C.G., Lawton, J.H., Shachak, M., 1994. Organisms as ecosystem engineers. In: Ecosystem Management. Springer, (New York, NY).

Kiraly, G., 2009. Uj magyar fuveszkonyv. Magyarorszag hajtasos novenyei. Hatarozokulcsok (New Hungarian Herbal. The Vascular Plants of Hungary. Identification Key). Aggtelek National Park Directorate, Josvafö [in Hungarian], 628 pp.

Kleyer, M., Bekker, R. M., Knevel, I. C., Bakker, J. P., Thompson, K., Sonnenschein, M., ... Peco, B. (2008). The LEDA Traitbase: A database of life-history traits of Northwest European flora. Journal of Ecology, 96, 1266-1274.

König, H. J., Ceaușu, S., Reed, M., Kendall, H., Hemminger, K., Reinke, H., .. \& Ford, A. T. (2021). Integrated framework for stakeholder participation: Methods and tools for identifying and addressing humanwildlife conflicts. Conservation Science and Practice, 3(3), e399. 
Limb, R. F., Engle, D. M., Bidwell, T. G., Althoff, D. P., Anderson, A. B., Gipson, P. S., \& Howard, H. R. (2010). Restoring biopedturbation in grasslands with anthropogenic focal disturbance. Plant Ecology, 210(2), 331-342.

Mallen-Cooper, M., Nakagawa, S., \& Eldridge, D. J. (2019). Global meta-analysis of soil-disturbing vertebrates reveals strong effects on ecosystem patterns and processes. Global Ecology and Biogeography, 28(5), 661-679.

McKechnie, S. (2006). Biopedturbation by an island ecosystem engineer: burrowing volumes and litter deposition by sooty shearwaters (Puffinus griseus ). New Zealand Journal of Zoology, 33(4), 259-265.

Molnár, Z. (2017). "I see the grass through the mouths of my animals" - Folk indicators of pasture plants used by traditional steppe herders. Journal of Ethnobiology, 37, 522-541.

Mosbech, A., Johansen, K. L., Davidson, T. A., Appelt, M., Grønnow, B., Cuyler, C., .. \& \& Flora, J. (2018). On the crucial importance of a small bird: The ecosystem services of the little auk (Alle alle) population in Northwest Greenland in a long-term perspective. Ambio, 47(2), 226-243.

Nevard, T. D., Leiper, I., Archibald, G., \& Garnett, S. T. (2018). Farming and cranes on the Atherton Tablelands, Australia. Pacific Conservation Biology, 25(2), 184-192.

Pesendorfer, M. B., Sillett, T. S., Koenig, W. D., \& Morrison, S. A. (2016). Scatter-hoarding corvids as seed dispersers for oaks and pines: a review of a widely distributed mutualism and its utility to habitat restoration. The Condor: Ornithological Applications, 118(2), 215-237.

Prange, H. (1999). Migration of Common Crane Grus grus in Europe. Vogelwelt, 120, 301-305.

R Core Team (2021). R: A language and environment for statistical computing. R Foundation for Statistical Computing, Vienna, Austria.

Rengifo-Faiffer, M. C., \& Arana, C. (2019). Fossorial birds help shape the plant community of a Peruvian desert. Journal of Arid Environments, 169, 29-33.

Romero, G. Q., Gonçalves-Souza, T., Vieira, C., \& Koricheva, J. (2015). Ecosystem engineering effects on species diversity across ecosystems: a meta-analysis. Biological Reviews, 90(3), 877-890.

Ter Braak, C.J.F., Šmilauer, P., 2012. CANOCO Reference Manual and User's Guide: Software for Ordination. Microcomputer power, Itaca, Wageningen version 5.0.

Valkó, O., Deák, B., Török, P., Kelemen, A., Miglécz, T., Tóthmérész, B., 2017. Filling up the gaps - Passive restoration does work on linear landscape scars. Ecol. Eng. 102, 501-508.

Valkó, O., Tölgyesi, C., Kelemen, A., Bátori, Z., Gallé, R., Rádai, Z., Bragina, T. M., Bragin, Y.A., Deák, B., 2021. Steppe Marmot (Marmota bobak) as ecosystem engineer in arid steppes. J. Arid Environ. 184, $104-244$.

Végvári, Z., 2002. Autumn staging and habitat selection by common cranesGrus grus in the Hortobágy National Park, Hungary. Folia Zoologica-Praha 51(3), 221-226.

Vicente-Gonzalez, L., Vicente-Villardon, J.L., 2021. PERMANOVA: Multivariate Analysis of Variance Based on Distances and Permutations. $R$ package version 0.2.0. https://CRAN.Rproject.org $/$ package $=$ PERMANOVA

Wetlands International. 2015. Waterbird Population Estimates. Available at: wpe.wetlands.org. (Accessed: $17 / 09 / 2015)$.

Whitford, W. G., \& Kay, F. R. (1999). Biopedturbation by mammals in deserts: a review. Journal of Arid Environments, 41(2), 203-230. 
Wilson, M.C., Smith, A.T. The pika and the watershed: The impact of small mammal poisoning on the ecohydrology of the Qinghai-Tibetan Plateau. Ambio 44, 16-22 (2015).

Yoshihara, Y., Ohkuro, T., Buuveibaatar, B., Undarmaa, J., Takeuchi, K., 2010b. Pollinators are attracted to mounds created by burrowing animals (marmots) in a Mongolian grassland. J. Arid Environ. 74 (1), $159-163$. 